\title{
National Water Management: The Central Planning Impetus
}

\section{Linden Vincent}

All legal systems acknowledge the fundamental importance of water in human activity, and the pattern of development of any society will promote rules and priorities to distribute water according to the needs of that society. As, however, patterns of use change, so must the law change: as pressures on supply increase, so must some allocative mechanism develop. A dichotomy has always existed in water management in that, whilst all historic legal codes recognize water to be in some kind of public domain, where the state protects certain uses, private rights may pertain to certain individuals. Community services seen to be lacking are organized first by local, often private, initiative in the form of associations or companies. It is as local initiative and traditional law become incapable of mobilizing or administering the water required, that the state can act in the public interest to introduce new legislation. Change in water management thus tends inexorably to be bound up with the emergence of central government, on the issue of operational efficiency and optimal allocation of resources alone. When water becomes of strategic economic and political significance, there arises also another planning requirement, equal in importance to the operational one in making the best use of resources. Water then becomes part of the national or regional strategy, and the recognition and delegation of water planning duties strongly influenced by national economic policy. The development in a water administration of these twin aims of national water planning capability and operational efficiency is crucially influenced by a central planning commitment, and the stimulus of a government regional policy.

Unfortunately a separation of planning and technical operations is all too possible in water management. Despite the emergence of a central goverment role in water resources, it may delegate only technical duties to water management units, retaining the planning duties itself, or perhaps even leaving these undefined. A set of nationwide regional water management units under a specific ministry can thus appear as a 'national' water administration although it has principally operational duties. For a water administration to be truly national, however, it should have planning responsibility within its own brief, and the dele- gation of this by the government is as important as the integration of fragmented operational units. It is the development of this planning capability with which this paper is particularly concerned.

The duties of a national water administration can be defined in the broadest sense as ensuring that water is available where it is needed at the least financial, environmental and social cost. For water to be available demands financial and planning capacity, technical expertise and maintenance capability. Identifying needs, and more importantly priorities, demands a wider economic awareness and definition of policy: financial, environmental and social costs are at their minimum when an integrated water supply strategy is pursued. These aspects demand both a vertical liaison between state, technical administration and users, and a horizontal liaison between the regional technical agencies themselves, as well as between government ministries. It is easy to see an essential pivotal role for a national water council explicitly linked to government policy-making, and with coordinatory powers over regional and local technical agents performing water duties. This will not emerge with a policy statement alone: indeed in many countries such a body may be seen as too independent for both local and government interests, as central involvement in water resources develops. Such a body develops alongside a planning structure which can integrate vertically and horizontally, as the water council itself must.

Case studies of the water administrations of France, United Kingdom, German Federal Republic, German Democratic Republic, Hungary and Mexico $^{1}$ show that an integrated water management system materializes only as governments become involved, explicitly or otherwise, in national or regional planning-indeed evidence from Mexico and West Germany suggests that water planning may be acting as a substitute for regional planning. The magnitude of this planning impetus depends on the 'strategic value' of water to a country: its real impact would depend on the strength of the central government and its ability to operate effectively at a regional and local level.

\footnotetext{
1 See UN, National Systems of Water Administraticn: a Comparative Study, 1973, and L. F. Vincent, The Correlation of Water Resources Management with Economic Growth and Political Institutions, unpublished MSc dissertation, University of Newcastle-upon-Tyne, 1974.
} 


\section{The Strategic Value of Water}

The natural environmental constraints versus the magnitude of demand might seem to be the main factor precipitating governmental interest, in both the actual limitation of resources available and its influence on population distribution and activity. Drier areas have built-in administrative difficulties in that the range of water development options is narrowest and most expensive where the range of demands is greatest. The costs of desalination and large-scale regional transfers mitigate against their use for an irrigation demand frequently greater than the domestic demand of the population depending on it. Hence there may be serious economic implications in the direct competition between agricultural and domestic water needs. Yet even in areas where attention is persistently called to the dearth of water, there may be little, if any, attention given to even the simplest conservatory measures. Regional planning is perhaps the only tool that can work on the economic implications of a water shortage, and provide for an agency to plan supplies and police water use.

In fact far greater implications for water management are carried in the technological advance which now enables water to play a large positive role in the development process. For countries/ regions undergoing development in the late 19thearly 20 th century, water played a comparatively minor role in the mobilization of agriculture and industry: the main dimension of water management lay in providing and protecting the supplies of large urban centres. The management need was thus narrow, and furthermore came one stage later in the development process, when urban industrial activity provided both a direct contribution to the financing of supplies and wageearning capacity that enabled rates or direct charges to be paid. Today hydroelectricity, flood control and irrigation schemes can provide a direct input into the 'building blocks' of the economy as well as being equally attractive as rural development tools. At the same time, many countries now face not only an urban supply problem exacerbated by shortage of finance from industry and rates, but also the fairly complex needs of a large rural population. Many LDCs thus face a water investment dilemma of power and water control versus urban water supply versus rural development.

It is not difficult in general to predict the most likely order of priorities which will be given to the above in the early stages of growth, or the equally predictable fragmentation of ministerial responsibility which will result. Thus while water development planning seems a promising tool for expanding the economic base of a region or country, it poses considerable administrative difficulties. It demands a high level of planning and economic expertise, with financial capability for initiating project development. At the same time it must be able to provide for the domestic and conservational needs which will occur as part of the devolopment process. This is the reverse of the pattern of administrative development experienced in most water management systems to date. For many LDCs, the first step in water resources legislation is the creation of some national water planning machinery which in turn develops regional technical units for data collection and hydraulic construction. Only later can attention be directed to rationalizing the management of water supply and sewerage. Many countries thus face problems in which the management experience of most industrialized countries is unable to assist: indeed the pre-eminence accorded to public health aspects by such countries may serve only to confuse the priority decisions a developing country must make.

Another feature of countries with a wide range of 'strategic' water uses, and hence LDCs in particular, is the extent to which traditional law and the current public interest is divorced from the aims of government and the resulting legislation. In countries where the problem is principally one of urban water supply and sewerage, the action of the government to protect supplies in the public interest' will be seen by the public as just that: it hurts a minority to benefit the majority. In countries where there is a complex relationship between water use, land tenure and agricultural activity, however, new laws will influence the majority and possibly restrict their livelihood in ways which may be incomprehensible to them. In such cases it is vital to have an economic understanding of local water problems when planning major water schemes at national level, and a high degree of liaison at regional and local level. This is unlikely to emerge without a central planning impetus.

\section{The Role of Central Government}

Central government involvement, and hence the concept of a national water administration, may develop specifically through the management of any one of the above interests. Yet it is nearly always conceived of in terms of a nationwide set of catchment-based units, and it is these that become the main regional counterparts of the national water administration, rather than any pre- 
existing water agencies. Such units begin with data collection duties, but these gradually extend to the policing of supply, hydraulic construction and eventually planning responsibilities, and thus involve the administration of other water needs. The evidence is, however, that domestic supply, irrigation schemes, and power develop quite different administrative solutions, which usually become established well before any government commitment to national water planning.

Most countries delegate water supply and sewerage duties either to branches of local government, or to associations with a strong municipal connection: these may rationalize into larger units, but the orientation remains the same. Irrigation and drainage schemes tend to be developed by more or less independent associations, especially where parts of large-scale rural development projects appear to be best served by 'ad hoc' semiautonomous agencies, with jurisdiction over land allocation, funds for provision of social infrastructure and some powers over industrial location and development. Power development falls logically within the preserve of such development agencies, but often the tendency is for hydroelectricity development to remain outside the brief of any regional water administration. This independence results from the early dimension of 'national significance' given to power, which predisposes it to centralized planning and administration, and may give little opportunity for the regional liaison necessary for the joint development of irrigation and power schemes.

The national water agency must liaise with all these structures; its pattern of development is thus bound up with the simplification of liaison difficulties as the concept of water management as a distinct unit becomes acknowledged. It is only in countries with a tradition of strongly independent local water management units that a concept of direct assumption of local functions by government agencies appears. Similarly cooperation at regional levels follows the example of inter-ministerial consultation at national level, and it is only in countries where this does not exist that one Ministry must attempt to 'hive-off' the responsibilities of another. The evidence is that no country experiencing such problems has yet developed fully comprehensive water management administrations: even if catchment management and water supply for either urban or agricultural needs are coordinated, it appears that full control is seldom, if ever, wrested from agricultural or power ministries.

The most serious problems of cooperation exist in federal or strongly nationalist government sys- tems. Federal governments face difficulties in coercing states to follow federal water laws, and to introduce their equivalent of the federal water agency, once the problem of cooperation between federal ministries is overcome. In nationalist systenus legislation frequently reflects the personal ideals of the leader, and there is often little continuity between successive governments. This serves to entrench ministerial interests to the point where it is usually easier to create a new ministry than coordinate existing ones. The interesting point here, however, is that as supply problems develop, states may agree to a form of water planning by some central agency which can substitute for regional planning if supplies are sufficiently critical. Thus even under conditions of severe distrust of central government, a central water agency will still develop at the expense of pre-existing managerial units and ministerial/state responsibilities although it may never have executive duties under such conditions.

\section{Conclusions}

Whatever the range of strategic water management needs, the tendency is for a national water administration to begin in a service capacity to the central government, and then to develop regional counterparts. Although the identity of the latter will depend on the economic significance of water, there is obviously a spectrum of potential for integrated water management which runs alongside that of centralization. Even so it is the extent to which this is taken up that determines the success of the water administration-the results of ministerial fragmentation in a highly bureaucratic system may make for a situation as bad as or worse than that in a country with no ministerial responsibility for water at all. Indeed, the experience of Russia and Eastern Europe demonstrates par excellence that the emergence of an integrated water administration depends on the explicit definition of a continuing state interest and involvement in water administration.

This paper began by separating the two issues of integrated operational functions and of planning capability as the aims of a national water administration. 'Source to tap' responsibility makes for rational operational management, but administrative success cannot be measured according to the breadth of executive duties alone. It is the link between the water administration and the government, between the ministers responsible for water within the government, and between the water agency and the regional administration, which is more important overall in the development of the administration. It is not sufficient to legislate on the role water is acknowledged to 
play. It is the ability to participate in the forward planning process which is the hallmark of the truly successful national water administration, which may thus have only limited operational duties. A defined and workable statement of government intention should be the first step in introducing a water management system. For the problems of mobilization, allocation and distribution of water to be overcome, a 'core' water unit which coordinates all regional technical agents and provides for an effective two-way transmission of information-relating projects for national growth to local management, and ensuring that local and regional change are encompassed in a national water strategy - will also be needed. It is, therefore, not surprising that even in countries of perennial water shortage it will be the strength or weakness of a central planning impetus that determines whether a truly national water management system will develop. 